Case Report

\title{
Acute Coronary Syndrome (ACS) due to Coronary Artery Embolism in a Patient with Atrial Fibrillation
}

\author{
Hussein Daoud ${ }^{1},{ }^{1}$ Ashraf Abugroun $\mathbb{D}^{1},{ }^{1}$ Shruti Erramilli, ${ }^{1}$ and Surender Kumar ${ }^{2}$ \\ ${ }^{1}$ Department of Internal Medicine, Advocate Illinois Masonic Medical Center, 836 W Wellington Ave., Chicago, IL 60657, USA \\ ${ }^{2}$ Department of Cardiology, Advocate Illinois Masonic Medical Center, 836 W Wellington Ave., Chicago, IL 60657, USA \\ Correspondence should be addressed to Hussein Daoud; hussein.daoud@advocatehealth.com
}

Received 3 April 2019; Revised 9 August 2019; Accepted 5 September 2019; Published 10 October 2019

Academic Editor: Aiden Abidov

Copyright ( 2019 Hussein Daoud et al. This is an open access article distributed under the Creative Commons Attribution License, which permits unrestricted use, distribution, and reproduction in any medium, provided the original work is properly cited.

\begin{abstract}
Acute coronary syndrome (ACS) secondary to a coronary embolism is an unusual occurrence, yet an important consideration given the difficult diagnosis. We report a case of a 69-year-old male with a medical history of paroxysmal atrial fibrillation who presented with chest pain and shortness of breath. A coronary angiogram was significant for three focal transluminal and translucent areas in the ostial, mid, and distal circumflex artery consistent with embolic disease. The patient was subsequently managed medically with anticoagulation. Despite being a relatively rare entity, thromboembolism into the coronary arteries can provoke an acute myocardial infarction, with atrial fibrillation being the most common risk factor. Treatment modalities for ACS secondary to thromboembolism include stent placement, intracoronary thrombolysis, and thrombus aspiration.
\end{abstract}

\section{Introduction}

Acute myocardial infarction secondary to a coronary embolism was first reported in 1856 by the famous German physician Rudolf Virchow [1]. Approximately $3 \%$ of acute coronary syndromes (ACS) are caused by a coronary embolism. Coronary emboli can arise through various mechanisms including a left atrial appendage thrombus due to atrial fibrillation, valve vegetations secondary to infective or autoimmune endocarditis, deep venous thrombi embolizing paradoxically through a patent foramen ovale (PFO), or iatrogenic secondary to coronary interventions [2]. Of these, atrial fibrillation is thought to be the most common etiology of coronary emboli, though there are few cases reported in the literature. Particularly, a non-ST-segment elevation myocardial infarction (NSTEMI) caused by embolic occlusion of a coronary artery in the setting of atrial fibrillation is a rare entity. The clinical presentation is like ACS of any cause. In this report, we discuss a case of a 69 -year-old male with a history of paroxysmal atrial fibrillation who presented with chest pain and exertional dyspnea. The coronary angiogram demonstrated three lesions in the ostial, mid, and distal circumflex artery consistent with emboli.

\section{Case Report}

A 69-year-old male presented to the emergency department complaining of chest pain and shortness of breath. His medical history was significant for paroxysmal atrial fibrillation on warfarin, coronary artery disease (CAD) with a proximal left anterior descending artery (LAD) stent, balloon valvuloplasty for severe aortic stenosis, and end-stage renal disease (ESRD) treated with peritoneal dialysis. The patient reported intermittent chest tightness that worsened with exertion and that was associated with progressive shortness of breath for one week before hospital arrival.

On admission, his heart rate was 104 beats per minute, blood pressure was $104 / 67 \mathrm{mmHg}$, respiratory rate was 22 breaths per minute, and the patient's oxygen saturation was above $94 \%$ on ambient air. The physical exam revealed a grade II/VI systolic ejection murmur over the aortic valve area. Labs showed a potassium of $5.8, \mathrm{BUN}$ of $65 \mathrm{mg} / \mathrm{dL}$, creatinine of $12.47 \mathrm{mg} / \mathrm{dL}$ (unknown baseline), hemoglobin of $8.4 \mathrm{~g} / \mathrm{dL}$, and a troponin I of $2.76 \mathrm{ng} / \mathrm{dL}$ (normal $<0.05$ ) that peaked on repeat at $3.79 \mathrm{ng} / \mathrm{dL}$. His international normalized ratio (INR) on admission was 2.0, though his compliance with anticoagulation and the INR in the weeks leading up 

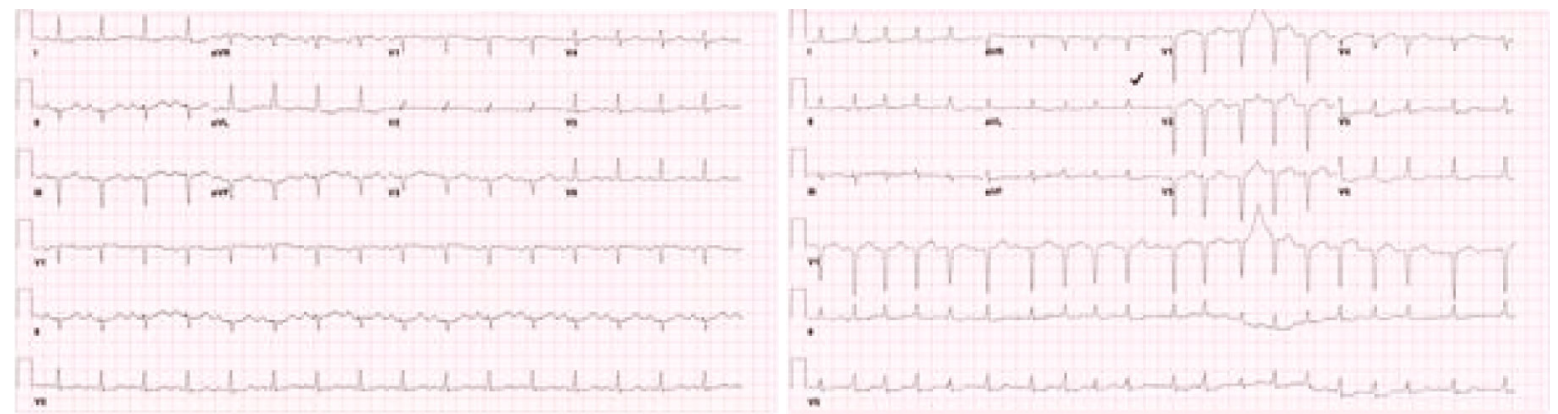

FIGURE 1: Admission electrocardiogram (ECG) on the left with a normal sinus rhythm and ECG on the right taken during the hospital stay showing atrial fibrillation with a rapid ventricular response.

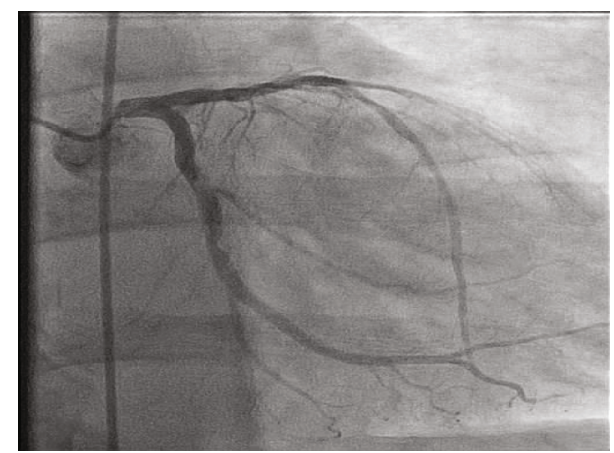

FIGURE 2: Left heart catheterization showing three focal transluminal and translucent areas in the ostial, mid, and distal circumflex artery that was mobile and hazy appearingconcerning for emboli.

to his admission was unknown. A chest X-ray was remarkable for mild cardiomegaly, interstitial pulmonary edema, and trace bilateral pleural effusions. An electrocardiogram (ECG) showed a normal sinus rhythm with an old apical infarct, and a transthoracic echocardiogram (TTE) revealed an ejection fraction of 15-20\% with grade two diastolic dysfunction and "possible" severe aortic valve stenosis (Figure 1).

The patient was diagnosed with a non-ST-segment elevation myocardial infarction (NSTEMI) and underwent both a right- and left-sided heart catheterization. The coronary angiogram revealed three focal transluminal and translucent areas in the ostial, mid, and distal circumflex artery consistent with coronary emboli (Figure 2). The left circumflex artery was otherwise angiographically normal. Given the patient's low ejection fraction and history of severe aortic stenosis, the interventional cardiologist recommended medical management with anticoagulation, instead of potential thrombolysis or thrombus aspiration, as he would be high risk for any coronary intervention.

A transesophageal echocardiogram (TEE) with agitated saline was subsequently ordered and did not reveal a patent foramen ovale (PFO), atrial septal defect (ASD), evidence of an embolic source (in the left atrial appendage or left ventricle), or any valve vegetation. The patient denied any episodes of chest pain or dyspnea during his hospital stay. He was deemed a poor candidate for aortic valve surgery by cardiothoracic surgery and was ultimately discharged on his home doses of aspirin, carvedilol, amiodarone, and warfarin with a follow-up for continued evaluation for a transcatheter aortic valve replacement (TAVR) procedure as his prior balloon valvuloplasty was completed as a bridging intervention.

\section{Discussion}

Individuals with atrial fibrillation are at an increased risk of thrombus formation in the left atrium, particularly in the left atrial appendage, through Virchow's triad of blood stasis, endothelial damage, and hypercoagulable state. They may also develop nonleft atrial appendage thrombi due to the overall diseased state of the atrium (atriopathy). This subsequently puts this population at an increased risk of thromboembolic events of the systemic circulation. Thromboembolism most often occurs during episodes of fibrillation or within the first ten days following cardioversion back to sinus rhythm. Sites of systemic embolism include the brain, splenic artery, renal artery, mesenteric artery, and limbs [3].

Myocardial infarction has been known to cause atrial fibrillation through multiple mechanisms, including ventricular ischemia/infarction and subsequent atrial stretching or directly through atrial ischemia [4]. Conversely, atrial fibrillation has been linked to myocardial infarction through its association with multiple atherosclerotic risk factors including diabetes, hypertension, and dyslipidemia. Additionally, atrial fibrillation is associated with inflammation that may promote a prothrombotic state and subsequent myocardial infarction. When these two conditions coincide, clinical management becomes more complex given the higher risk of bleeding when combining anticoagulant and antiplatelet medications [5].

The phenomenon of thromboembolism into the coronary arteries is rare with an unknown prevalence given its difficult diagnosis. Acute myocardial infarction secondary to a coronary embolism was first reported in 1856 by the famous German physician Rudolf Virchow [1]. In patients with myocardial infarction, 4-7\% are found to not have atherosclerotic vascular disease [6]. In an autopsy study of 419 patients, $55(13 \%)$ were found to have an embolic infarct in their coronary arteries [7]. A study by Shibata et al. looked at new-onset acute myocardial infarctions between 2001 and 2013, and 1776 consecutive cases were analyzed with a focus on coronary embolism (CE) diagnosis through angiography, histology, and imaging. In that study, 52 patients were acknowledged to have CE (2.9\%) and the most common 
TABLE 1: Reported cases of coronary artery embolism with embolus location and outcomes.

\begin{tabular}{|c|c|c|c|c|c|c|c|}
\hline Author & $\begin{array}{l}\text { Patient } \\
\text { age }\end{array}$ & $\begin{array}{l}\text { Patient } \\
\text { gender }\end{array}$ & $\begin{array}{l}\text { History } \\
\text { of atrial } \\
\text { fibrillation } \\
\text { or flutter }\end{array}$ & Peak troponin & Embolus location & Outcomes & References \\
\hline Antoine et al. & 58 & M & Yes. & $\begin{array}{l}\text { Troponin I } 9.56 \\
\text { (unknown units). }\end{array}$ & $\begin{array}{l}\text { Distal left circumflex } \\
\text { artery (LCX). }\end{array}$ & $\begin{array}{l}\text { NSTEMI managed } \\
\text { by embolectomy. }\end{array}$ & {$[12]$} \\
\hline Camaro et al. & 66 & $\mathrm{~F}$ & $\begin{array}{c}\text { Yes, } \\
\text { new-onset. }\end{array}$ & Unknown. & $\begin{array}{l}\text { Distal right coronary } \\
\text { artery (RCA). }\end{array}$ & $\begin{array}{c}\text { STEMI managed } \\
\text { conservatively with } \\
\text { anticoagulation after } \\
\text { failed PCI. }\end{array}$ & {$[13]$} \\
\hline Diaz et al. & 52 & M & $\begin{array}{c}\text { Yes, } \\
\text { new-onset. }\end{array}$ & $\begin{array}{l}\text { Troponin I } 0.6 \mathrm{ng} / \mathrm{mL} \\
\quad(\text { normal }<0.024) .\end{array}$ & $\begin{array}{c}\text { Proximal left } \\
\text { anterior descending } \\
\text { artery (LAD). }\end{array}$ & $\begin{array}{l}\text { NSTEMI managed } \\
\text { by thrombectomy. }\end{array}$ & {$[14]$} \\
\hline Everett et al. & 30 & M & No. & Unknown. & Distal LAD. & $\begin{array}{l}\text { Acute coronary } \\
\text { syndrome managed } \\
\text { by thrombectomy } \\
\text { and anticoagulation. }\end{array}$ & [9] \\
\hline Garg et al. & 53 & $\mathrm{~F}$ & $\begin{array}{l}\text { New-onset } \\
\text { atrial } \\
\text { fibrillation. }\end{array}$ & $\begin{array}{l}\text { Troponin T } 5.0 \mathrm{ng} / \mathrm{mL} \\
(\text { normal }<0.10 \mathrm{ng} / \mathrm{mL} \text { ). }\end{array}$ & $\begin{array}{c}\text { Posterolateral } \\
\text { branch of the LCX. }\end{array}$ & $\begin{array}{l}\text { NSTEMI managed } \\
\text { with anticoagulation. }\end{array}$ & {$[15]$} \\
\hline \multirow[b]{3}{*}{ Kotooka et al. } & 88 & $\mathrm{~F}$ & Yes. & Unknown. & Proximal RCA. & $\begin{array}{l}\text { STEMI managed by } \\
\text { thrombectomy. }\end{array}$ & \\
\hline & 50 & M & No. & Unknown. & Ostium of RCA. & $\begin{array}{l}\text { STEMI treated by } \\
\text { thrombus aspiration. }\end{array}$ & \\
\hline & 85 & M & Yes. & Unknown. & $\begin{array}{l}\text { Left main coronary } \\
\text { artery (LCA). }\end{array}$ & $\begin{array}{l}\text { STEMI complicated } \\
\text { by cardiogenic } \\
\text { shock, managed by } \\
\text { dobutamine and an } \\
\text { intra-aortic balloon } \\
\text { pump and } \\
\text { subsequently a } \\
\text { thrombectomy and } \\
\text { stent placement. }\end{array}$ & {$[16]$} \\
\hline $\begin{array}{l}\text { Koutsampasopoulos } \\
\text { et al. }\end{array}$ & 69 & $\mathrm{~F}$ & Yes. & $\begin{array}{l}\text { High sensitivity } \\
\text { troponin } \mathrm{T} 5.33 \mathrm{ng} / \mathrm{L} \\
\quad(\mathrm{N}<0.014) .\end{array}$ & Midsegment of LAD. & $\begin{array}{l}\text { STEMI managed } \\
\text { with thrombectomy. }\end{array}$ & {$[17]$} \\
\hline Nakano et al. & 82 & $\mathrm{~F}$ & Yes. & Troponin I $0.65 \mathrm{ng} / \mathrm{mL}$. & $\begin{array}{c}\text { Unclear. ECG } \\
\text { showed atrial } \\
\text { fibrillation, an } \\
\text { inverted T wave in } \\
\text { V1-V3, an abnormal } \\
\text { Q wave in V1 -V4, } \\
\text { and ST-segment } \\
\text { elevation in V3 and } \\
\text { V4. }\end{array}$ & $\begin{array}{l}\text { The patient was too } \\
\text { unstable for an } \\
\text { angiogram, thus was } \\
\text { treated with } \\
\text { intravenous heparin } \\
\text { but died within } 24 \\
\text { hours (diagnosis } \\
\text { suspected by criteria } \\
\text { proposed by Shibata } \\
\text { et al.). }\end{array}$ & {$[11]$} \\
\hline OSullivan et al. & 70 & M & $\begin{array}{c}\text { Perioperative } \\
\text { atrial } \\
\text { fibrillation } \\
\text { after } \\
\text { noncardiac } \\
\text { surgery with } \\
\text { subsequent } \\
\text { embolization. }\end{array}$ & $\begin{array}{l}\text { High sensitivity } \\
\text { troponin T } 0.540 \mu \mathrm{g} / \mathrm{L} \\
(\text { normal }<0.014) \text {. }\end{array}$ & $\begin{array}{l}\text { Complete occlusion } \\
\text { of RCA up to ostium. }\end{array}$ & $\begin{array}{l}\text { STEMI managed } \\
\text { with thrombectomy. }\end{array}$ & {$[18]$} \\
\hline Sakai et al. & 72 & M & Yes. & $\begin{array}{l}\text { Unknown, CKMB } \\
\text { peaked at } 2929 \mathrm{IU} / \mathrm{L} \\
\text { (normal }<180) .\end{array}$ & Proximal RCA. & $\begin{array}{l}\text { STEMI managed } \\
\text { by thrombectomy. }\end{array}$ & [19] \\
\hline
\end{tabular}


TABLE 1: Continued.

\begin{tabular}{lcccccc}
\hline Author & $\begin{array}{c}\text { Patient } \\
\text { age }\end{array}$ & $\begin{array}{c}\text { Patient } \\
\text { gender }\end{array}$ & $\begin{array}{c}\text { History } \\
\text { of atrial } \\
\text { fibrillation } \\
\text { or flutter }\end{array}$ & Peak troponin & Embolus location & Outcomes \\
\hline Takenaka et al. & 65 & F & Yes. & Unknown. & Distal LAD. & $\begin{array}{c}\text { STEMI managed by } \\
\text { balloon angioplasty } \\
\text { and thrombolysis. }\end{array}$ \\
\hline Van de Walle et al. & 64 & M & Yes. & Unknown. & Midsegment of LAD. & $\begin{array}{c}\text { STEMI managed by } \\
\text { stenting. }\end{array}$ \\
\hline Zakaria et al. & 65 & F & $\begin{array}{c}\text { New-onset } \\
\text { atrial flutter. }\end{array}$ & Unknown. & Origin of LCX. & $\begin{array}{c}\text { NSTEMI managed } \\
\text { by thrombectomy. }\end{array}$ \\
\hline
\end{tabular}

etiologies were atrial fibrillation, cardiomyopathy, and valvular heart disease with a prevalence of $73 \%, 25 \%$, and $15 \%$, respectively [8].

Therefore, even though atrial fibrillation is thought to be the most common risk factor, other potential sources for coronary embolization exist. These include a left ventricular mural thrombus from a prior myocardial infarction, thromboemboli from the trabeculated myocardium in noncompaction cardiomyopathy, or intrapulmonary shunting through arteriovenous malformations or fistulae $[9,10]$. However, cardiac magnetic resonance imaging (MRI), computed tomography angiography (CTA) chest, or ventilationperfusion (VQ) studies, which could identify some of these other potential causes, were not pursued in this patient.

Coronary embolisms can manifest as a non-ST-segment elevation myocardial infarction (NSTEMI) like in our patient or an ST-segment elevation myocardial infarction (STEMI) as seen in other case reports (Table 1). The condition has also been seen in the setting of a concomitant stroke and diffuse systemic embolization [11]. The National Cerebral and Cardiovascular Center (NCVC) criteria for the clinical diagnosis of coronary artery embolism (CE) was proposed by Shibata et al. and uses combinations of major and minor criteria to categorize the diagnosis of CE into definite or probable [8] (Table 2). In that study, out of the 52 patients, 32 met the definitive criteria and 20 the probable criteria. Based on the proposed criteria, our patient would fall under the category of "probable" CE given the angiographic findings and risk factor of atrial fibrillation (one major and one minor criterion). Although no embolic source was found on echocardiography, the absence does not rule out CE.

In our case report, the patient was managed medically with anticoagulation given his high risk for coronary intervention, but additional therapeutic options exist that are consistent with other causes of ACS including stent placement, intracoronary thrombolysis, and thrombus aspiration-which is generally favored because of the decreased risk of distal embolization [1].

\section{Conclusion}

Coronary embolism is an unusual and therefore likely an underreported etiology of ACS. Patients often have varying levels of concurrent atherosclerosis which can further confound the picture. Distinctions can, however, be made
TABle 2: Proposed National Cerebral and Cardiovascular Center (NCVC) criteria for the clinical diagnosis of coronary artery embolism (CE) [1].

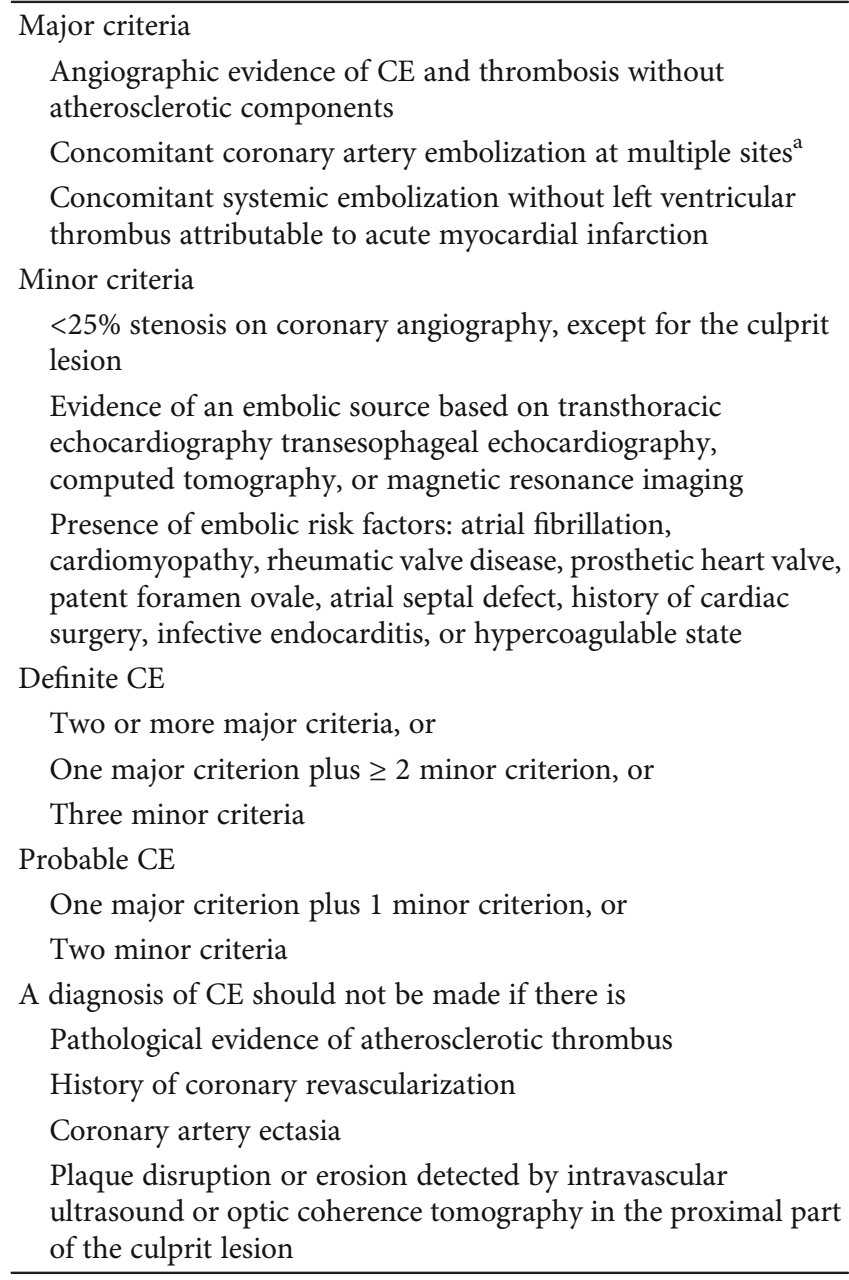

The present proposed diagnostic criteria for $\mathrm{CE}$ include three major and three minor criteria. Weighted scoring of the criteria is used to differentiate between definite and probable $\mathrm{CE}$ in patients with acute myocardial infarction. ${ }^{\mathrm{a}}$ Multiple vessel within one coronary artery territory or multiple vessels in the coronary tree. Note: this table is reproduced from Nakano $\mathrm{H}$, Yamagami H, Ofuchi H. A case report of systemic embolic events associated with atrial fibrillation. Acute Medicine \& Surgery 2017;4:12730. doi:10.1002/ams2.235. 
angiographically. Management is the same for both: anticoagulation, thrombolysis, and percutaneous coronary intervention (PCI). Thrombus aspiration may be considered in patients with a heavy thrombus burden. However, following initial management, it is vital to further investigate the source of emboli in these patients. It is important to contemplate atrial fibrillation not only as a consequence of ACS but also as a cause of it. Additionally, it is important to consider bleeding risks given the need for both anticoagulation and antiplatelet therapy in these groups of patients.

\section{Conflicts of Interest}

The authors declare that there are no conflicts of interest regarding the publication of this paper.

\section{Supplementary Materials}

Left heart catheterization showing three focal transluminal, translucent areas in the ostial, mid, and distal circumflex artery that was mobile and hazy appearing-concerning for emboli. (Supplementary Materials)

\section{References}

[1] S. Van de Walle and K. Dujardin, "A case of coronary embolism in a patient with paroxysmal atrial fibrillation receiving tamoxifen," International Journal of Cardiology, vol. 123, no. 1, pp. 66-68, 2007.

[2] C. E. Raphael, J. A. Heit, G. S. Reeder et al., "Coronary embolus," JACC: Cardiovascular Interventions, vol. 11, no. 2, pp. 172-180, 2018.

[3] J. Menke, L. Lüthje, A. Kastrup, and J. Larsen, “Thromboembolism in atrial fibrillation," The American Journal of Cardiology, vol. 105, no. 4, pp. 502-510, 2010.

[4] M. Alasady, N. J. Shipp, A. G. Brooks et al., "Myocardial infarction and atrial fibrillation: importance of atrial ischemia," Circulation: Arrhythmia and Electrophysiology, vol. 6, no. 4, pp. 738-745, 2013.

[5] F. Violi, E. Z. Soliman, P. Pignatelli, and D. Pastori, "Atrial fibrillation and myocardial infarction: a systematic review and appraisal of pathophysiologic mechanisms," Journal of the American Heart Association, vol. 5, no. 5, 2016.

[6] B. Waller, B. F. Waller, E. T. A. Fry, J. B. Hermiller, T. Peters, and J. D. Slack, "Nonatherosclerotic causes of coronary artery narrowing_part II," Clinical Cardiology, vol. 19, no. 7, pp. 587-591, 1996.

[7] K. R. Prizel, "Coronary artery embolism and myocardial infarction: a clinicopathologic study of 55 patients," Annals of Internal Medicine, vol. 88, no. 2, pp. 155-161, 1978.

[8] T. Shibata, S. Kawakami, T. Noguchi et al., "Prevalence, clinical features, and prognosis of acute myocardial infarction attributable to coronary artery embolism," Circulation, vol. 132, no. 4, pp. 241-250, 2015.

[9] M. E. Everett, J. N. Kirkpatrick, and R. M. Lang, "Noncompaction of the myocardium complicated by coronary artery embolism," Journal of the American Society of Echocardiography, vol. 18, no. 2, pp. 194-196, 2005.

[10] S. Windecker, S. Stortecky, and B. Meier, "Paradoxical embolism," Journal of the American College of Cardiology, vol. 64, no. 4, pp. 403-415, 2014.
[11] H. Nakano, H. Yamagami, and H. Ofuchi, "A case report of systemic embolic events associated with atrial fibrillation," Acute Medicine \& Surgery, vol. 4, no. 1, pp. 127-130, 2017.

[12] S. Antoine, D. Lowe, K. Jessamy, O. Anozie, and V. Frechette, "Myocardial infarction caused by coronary artery thromboembolism in a atrial fibrillation patient on rivaroxaban," Chest, vol. 150, no. 4, article 100A, 2016.

[13] C. Camaro and W. R. M. Aengevaeren, "Acute myocardial infarction due to coronary artery embolism in a patient with atrial fibrillation," Netherlands Heart Journal, vol. 17, no. 8, pp. 297-299, 2009.

[14] J. C. Díaz, D. Weir, W. Uribe et al., “Acute myocardial infarction due to coronary embolism in atrial fibrillation: case presentation and systematic review," Revista Mexicana de Cardiolog, vol. 27, no. 4, pp. 171-180, 2016.

[15] R. K. Garg and N. Jolly, "Acute myocardial infarction secondary to thromboembolism in a patient with atrial fibrillation," International Journal of Cardiology, vol. 123, no. 1, pp. e18e20, 2007.

[16] N. Kotooka, Y. Otsuka, S. Yasuda, I. Morii, A. Kawamura, and S. Miyazaki, "Three cases of acute myocardial infarction due to coronary embolism: treatment using a thrombus aspiration device," Japanese Heart Journal, vol. 45, no. 5, pp. 861-866, 2004.

[17] K. Koutsampasopoulos, A. Datsios, S. Grigoriadis, and I. Vogiatzis, "Atrial fibrillation causing ST elevation myocardial infarction due to coronary embolism: case report and review of the literature," Hippokratia, vol. 20, no. 2, pp. 160$162,2016$.

[18] C. J. OSullivan, M. Sprenger, D. Tueller, and F. R. Eberli, “Case report: coronary thromboembolic acute myocardial infarction due to paroxysmal atrial fibrillation occurring after noncardiac surgery,” BMJ Case Reports, vol. 2015, 2015.

[19] K. Sakai, K. Inoue, and M. Nobuyoshi, "Aspiration thrombectomy of a massive thrombotic embolus in acute myocardial infarction caused by coronary embolism," International Heart Journal, vol. 48, no. 3, pp. 387-392, 2007.

[20] T. Takenaka, M. Horimoto, K. Igarashi, H. Yoshie, I. Tsujino, and M. Morihira, "Multiple coronary thromboemboli complicating valvular heart disease and atrial fibrillation," American Heart Journal, vol. 131, no. 1, pp. 194-196, 1996.

[21] A. Zakaria, B. A. Share, G. Kaspar, and D. Small, "A fluttering coronary event," Journal of Family Medicine and Primary Care, vol. 7, no. 2, pp. 468-470, 2018. 


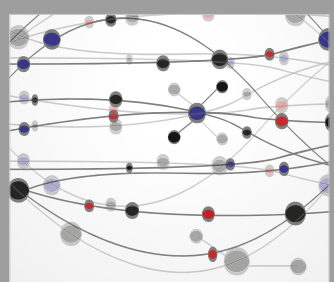

The Scientific World Journal
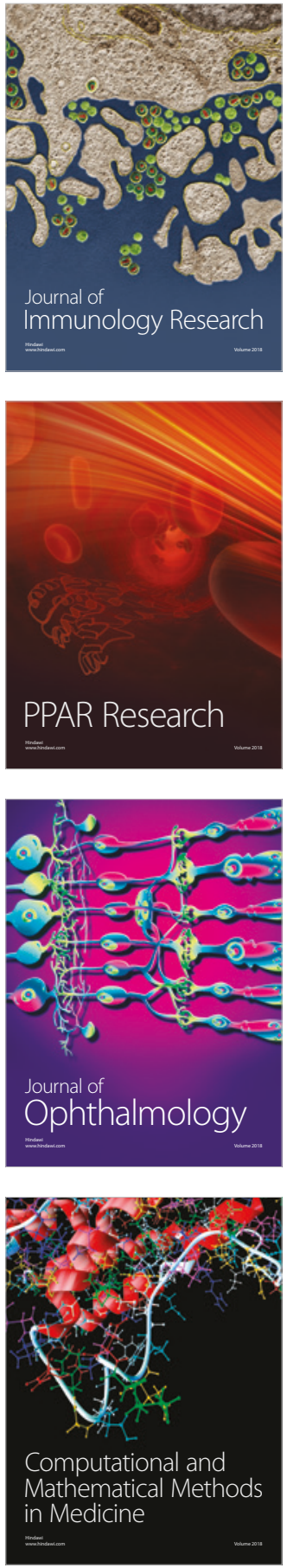

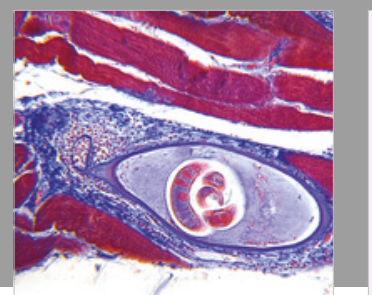

Gastroenterology Research and Practice

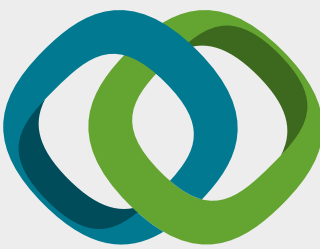

\section{Hindawi}

Submit your manuscripts at

www.hindawi.com
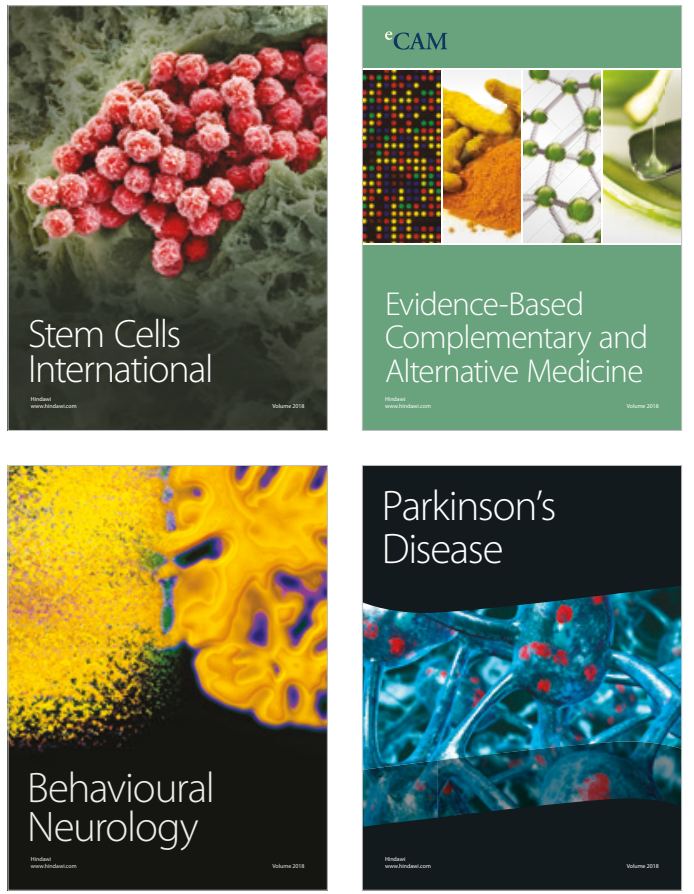

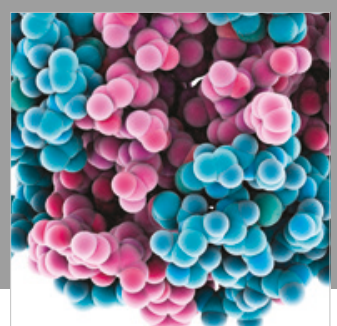

ournal of

Diabetes Research

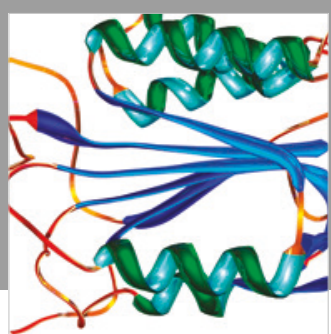

Disease Markers
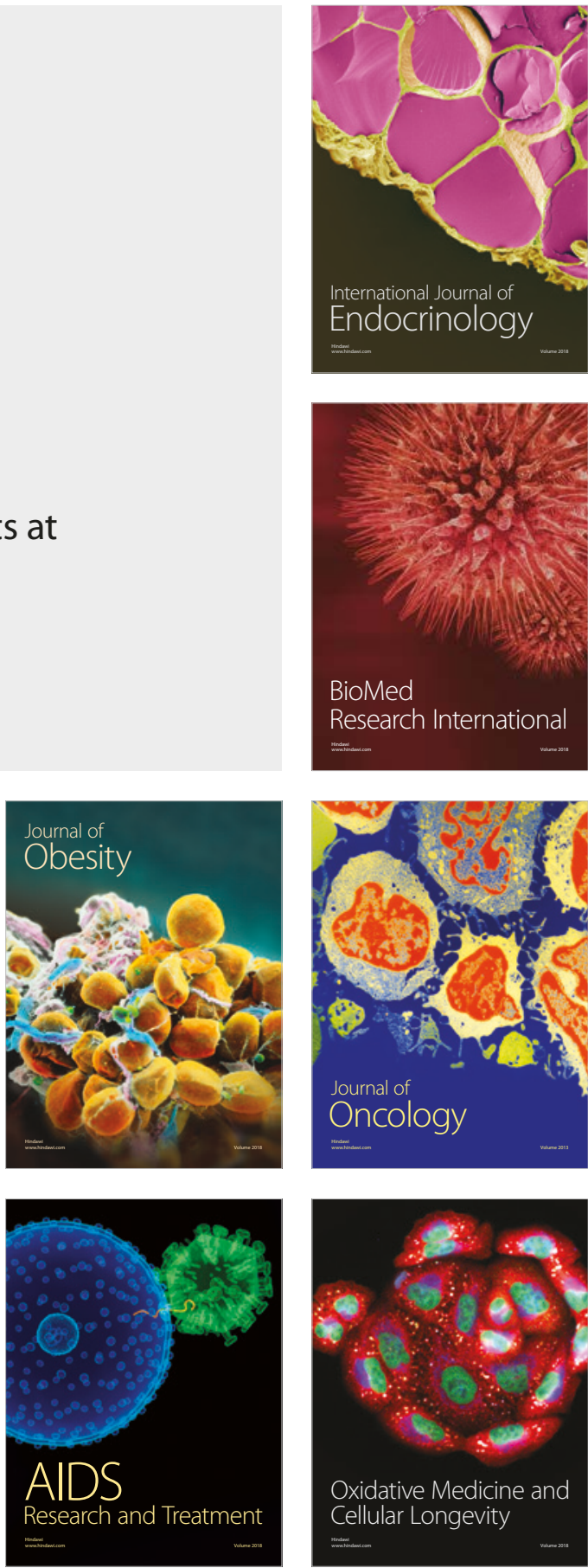